\title{
Değişik Tarımsal Atıkların Bazı Kültür Mantarı Türlerinin Besin Değerleri Üzerine Etkisi
}

\section{Sevda KIRBAĞ, Volkan KORKMAZ}

Fırat Üniversitesi, Fen Fakültesi, Biyoloji Bölümü, Elazığ

\section{Eser Bilgisi:}

Araştırma makalesi

Sorumlu yazar: Sevda KIRBAĞ, e-mail:skirbag@firat.edu.tr

doi: http://dx.doi.org/10.17474/acuofd.35282

\section{ÖZET}

$\mathrm{Bu}$ çalışmada, değişik tarımsal atık üzerinde yetiştirilen, Pleurotus ostreatus (Jacq.ex.Fr) kum. Pleurotus florida (Mont.) Singer, P. sajor-caju (Fr.) Singer nin besin bileşimleri ve element içerikleri belirlendi. Mantar türlerinde. \% 86.6-91.7 kuru madde, \% 8.3-13.4 nem, \% 26.3-39.3 ham protein, \% 0.5-4.5 ham yağ, \% 4.4-7.8 ham kül, \% 34.248.9 azotsuz öz madde içerdiği ve element içeriklerinin ise değiştiği saptanmıştır. En yüksek protein içeriği; $P$. sajorcaju’nun kültürünün yapıldığı B-C ortamında \% 39.3 ve $P$. ostreatus' un yetiştirildiği B ortamında ise \% 36.4 olarak tespit edilmiştir.

Anahtar Kelimeler: Kültür mantarı, besin, tarımsal ve endüstriyel atık, Pleurotus spp.

Effect on the Nutritional Value of Some Cultivated Mushroom Species of Various Agricultural Waste Materials

Article Info:

Research article

Corresponding author: Sevda KIRBAĞ, e-mail: skirbag@firat.edu.tr

\section{ABSTRACT}

In this study; The nutritional composition and element contents of Pleurotus ostreatus (Jacq.ex.Fr) kum., Pleurotus florida fovose, P. sajor-caju (Fr.) Singer, which grown on some various agro-wastes were determined. Mushroom species. contained that $86.6-91.7 \%$ dry matter, moisture $8.3-13.4 \%, 26.3-39.3 \%$ crude protein, $0.5-4.5 \%$ crude fat, 4.4-7.8\% crude ash, 34.2-48.9\% nitrogen-free extract substances, and it was found that the change of element content. The highest protein content was determined in BC environment that the culture of P. sajor-caju as \% 39.3, and in B growing medium that the culture of P. ostreatus was determined as $36.4 \%$.

Key words: Mushroom, nutrition, agriculturel and industrial waste, Pleurotus spp.

\section{GİRIS}

Makrofunguslar, yaklaşık 1000 yıldır insanoğlu tarafından; düşük yağ ve kalori değerleri ile doymamıs yağ asidi, zengin mineral elementler, vitamin, amino asit, karbonhidrat ve protein gibi besleyici değerleri için düzenli diyetin bir parçası (Breene 1990; Mattila ve ark. 2000), lezzetleri, aroma içerikleri ve aşçılık ile ilgili olan özelliklerinden dolayı bir besin kaynağı olarak (Manzi ve ark. 1999; Mattila ve ark. 2001), tıbbi ve tedavi edici özellikleri ile günümüze kadar farklı amaçlar için kullanılmıştır (Cohen ve ark. 2002).
Bir çok ülkede üreticiler tarafindan en fazla kültürü yapılan türlerin; Agaricus spp., Lentitus edodes, Pleurotus spp., Volvariella volvace (Bull ex. fr.) Singer Auricularia spp., Genoderma spp., Flammulina velutipes (Fr.) P. Karst. olduğu belirlenmiştir (Diez ve Alvarez 2001). Pleurotus spp.'nin tüm dünyada en fazla üretilen mantar türleri içerisinde, Agaricus spp. ve $L$. edodes'ten sonra 3 . sirada yer aldığı ve üretim miktarının ise, yıllık bir milyon tondan daha fazla olduğu, şapka yapılarının; midye kabuğu ve spatul benzeri, sap yapilarının ise eksantrik veya lateral olmalarından dolayı istiridye mantarları (oyster mushroom)" olarak adlandırılmaktadırlar (Cohen ve ark. 2002; 
Crisand ve Sand 1978). Pleurotus spp.'nin; tıbbi özellikleri, zengin besinsel içerikleri, kısa yaşam döngüleri, üretimlerinin düşük teknolojik maliyetle sağlanması, tarımsalendüstriyel atıklar üzerinde kolaylıkla üretilebilmeleri, hastalık ve zararlılar yönünden ise dayanıklı olmalarından dolayı, dünyanın pek çok ülkesinde ticari olarak kültürleri yapılmaktadır (Ragunathan ve ark. 1996; Ragunathan ve Swaminathan 2003).

Funguslar, tarımsal atıkları biyolojik olarak parçalayabilmelerinden dolayı ekosistem üzerinde önemli bir yere sahiptirler (Gücin ve Tamer 1997). Lignosellülozik tarımsal atıkların, mantar kültüründe değerlendirilmesi, bu konunun önemini arttırmaktadır. Anız yakma ile imha edildiğinde ekolojik çevre üzerinde olumsuz etkileri olduğu bilinen bu atıkların; bir besin maddesi üretiminde değerlendirilmesi, hem çevrenin korunmasına, hem de önemli bir besin kaynağının üretilmesine olanak sağlayacak ve yetiştirilmesi sırasında, yeni iş gücüne ihtiyaç duyulacak, bölge ve ülke ekonomisine de katkı sağlayacaktır. Kültür mantarı üretimi, bu problemlerin çözüm yollarından sadece biri olarak düşünülmektedir (Cohen ve ark. 2002).

Bu çalışmada, bölgemiz şartllarında bol ve ucuz olarak sağlanabilen; buğday sapı, şeker pancarı küspesi ile ceviz kabuğu gibi tarımsal ve endüstriyel atıkların; $P$. ostreatus, $P$. florida ve $P$. sajor-caju kültürlerinde kullanılarak, besin değerleri üzerine etkileri araştırılmıştır.

\section{MATERYAL VE METOD}

$\mathrm{Bu}$ çalışmada kullanılan mantar örnekleri, önceki kültür çalışmalarından elde edilmiştir (Kırbağ ve Korkmaz 2013). Değişik kültür ortamlarından elde edilen mantar örneklerinin; kuru madde, nem, ham kül, ham protein, ham yağ ve element içerikleri ilgili literatürdeki analiz yöntemlerine göre yapılmıştır (AOAC 1990; Ergün ve ark. 2004). İstatistiksel analizlerler, standart paket program ile yapılmış olup, deneysel çalışmaların karşılaştırılmasında tek yönlü varyans analizi (ANOVA) uygulandıktan sonra, verilerin analizinde Tukey HSD çoklu karşılaştırma testi kullanılmıştır. Gruplar arasındaki fark $\mathrm{P}<0.05$ olduğu zaman önemli kabul edilmiştir.

\section{BULGULAR ve TARTIŞMA}

Değişik tarımsal atıklar üzerinde kültürü yapilan $P$. ostreatus'da \% 86.6-89.8 kuru madde, \% 10.2-13.4 nem, \% 26.3-36.4 ham protein, \% 0.5-1.8 ham yağ, \% 4.9-5.7 ham kül, \% 38.5-43.5 azotsuz öz madde, 102.9-176.6 $\mathrm{mg} / \mathrm{kg} \mathrm{Na}, 194.7-239.9 \mathrm{mg} / \mathrm{kg} \mathrm{K}, 0-40 \mathrm{mg} / \mathrm{kg}$ $\mathrm{Cu}, 53-739 \mathrm{mg} / \mathrm{kg}$ Fe, $280-508 \mathrm{mg} / \mathrm{kg}$ Zn, 3.51$14.65 \mathrm{mg} / \mathrm{kg} \mathrm{Pb}$. P. florida'da \% 90.5-91.6 kuru madde, \% 8.4-9.6 nem, \% 27.3-32.8 ham protein, \% 1.5-2.4 ham yağ, \% 4.4-6.7 ham kül, \% 44.0-48.9 azotsuz öz madde, 128.4-185.2 $\mathrm{mg} / \mathrm{kg} \mathrm{Na}, 344.4-379.4 \mathrm{mg} / \mathrm{kg} \mathrm{K}, 0-459 \mathrm{mg} / \mathrm{kg}$ Fe, 387-413 mg/kg Zn, 0.98-3.95 mg/kg Pb. P. sajor-caju'da \% 87.1-91.7 kuru madde, \% 8.312.9 nem, $\%$ 28.9-39.3 ham protein, $\%$ 0.6-4.5 ham yağ, \% 6.4-7.8 ham kül, \% 34.2-40.2 azotsuz öz madde, 90.1-136.9 mg/kg Na, 166.0$401.7 \mathrm{mg} / \mathrm{kg} \mathrm{K}, 0-545 \mathrm{mg} / \mathrm{kg}$ Fe, 310-425 mg/kg $\mathrm{Zn}, 0.0-1.98 \mathrm{mg} / \mathrm{kg} \mathrm{Pb}$ içerdiği, fakat tüm türlerde ise $\mathrm{Co}, \mathrm{Mn}, \mathrm{Cu}$ ve $\mathrm{Ni}$ gibi toksik metaller ise tespit edilmemiştir (Tablo 1-2).

Genellikle; kuru mantar örneklerinde yaklaşık \% 90 kuru madde, \% 10 nem veya taze örneklerde ise \% 90 su ve \% 10 oranında kuru madde içermektedir (Crisand and Sand 1978; Ragunathan ve Swaminathan 2003; Akyüz ve Kırbağ 2010, Ranzai ve Sturion 1998; Morais ve ark. 2000; Bano ve ark. 1981; Yang ve ark. 2001; Oyetayo ve Akindahunsi 2004; Çağlarırmak 2007).

Yabani ve kültür mantarlarının ( $P$. florida, $P$. ostreatus, P. eous, P. sajor caju, P. cystidiosus) protein içeriği; $\% \quad 10.5-51.25$ olarak değişmektedir (Akyüz ve Kırbağ 2010; Crisand and Sand 1978; Ragunathan ve Swaminathan 2003; Bano ve Rajarathnam 1988; Yıldız Karakaplan 2003; Küçükomuzlu ve Peksen 2005; Chang ve Miles 1989; Yang ve ark. 2001; Rashad ve Abdou 2002; Oyetayo ve Akindahunsi 2004). Lokal atıklar üzerinde kültürü yapılan $P$. ostreatus' da \% 26.3-36.4 ham protein, $P$. florida'da \% 27.3-32.8 ham protein ve $P$. sajor-caju'da ise \% 28.9-39.3 ham protein tespit edilmiştir (Tablo 1). 
Tablo 1. Değişik kültür ortamlarında yetiştirilen bazı mantar türlerinin besinsel içerikleri

\begin{tabular}{|c|c|c|c|c|c|c|c|c|c|c|c|c|c|c|c|c|c|c|}
\hline & \multicolumn{3}{|c|}{ Kuru madde } & \multicolumn{3}{|c|}{$\mathrm{Nem}$} & \multicolumn{3}{|c|}{ Ham proteın } & \multicolumn{3}{|c|}{ Ham yağ } & \multicolumn{3}{|c|}{ Ham kül } & \multicolumn{3}{|c|}{ Karbonhidrat } \\
\hline & $\mathrm{PO}$ & PSC & PF & $\mathrm{PO}$ & PSC & PF & $\mathrm{PO}$ & PSC & $\mathrm{PF}$ & $\mathrm{PO}$ & PSC & $\mathrm{PF}$ & $\mathrm{PO}$ & PSC & PF & $\mathrm{PO}$ & PSC & $\mathrm{PF}$ \\
\hline B & $\begin{array}{l}.8 \pm 0 . \\
\text { axy }\end{array}$ & $\begin{array}{l}1 \pm 1 . \\
\text { ay }\end{array}$ & $\begin{array}{l}.8 \pm 0.4 \\
\mathrm{ax}\end{array}$ & $\begin{array}{l}2 \pm 0.1 \\
\text { axy }\end{array}$ & $\begin{array}{c}12.9 \pm 1.4 \\
\text { ay }\end{array}$ & $\begin{array}{c}9.2 \pm 0.4 \\
\mathrm{ax}\end{array}$ & $\begin{array}{l}6.4 \pm 0.1 \\
\operatorname{ax}\end{array}$ & $28.9 \pm 0.4$ & $\begin{array}{c}32.8 \pm 0.9 \\
a z\end{array}$ & $\begin{array}{c}0.5 \pm 0.3 \\
\mathrm{ax}\end{array}$ & $\begin{array}{c}3.7 \pm 0.1 \\
\text { ay }\end{array}$ & $\begin{array}{c}2.3 \pm 0.5 \\
\mathrm{az}\end{array}$ & $\begin{array}{c}4.9 \pm 0.2 \\
\mathrm{ax}\end{array}$ & $\begin{array}{c}6.4 \pm 0.0 \\
\text { ay }\end{array}$ & $4.4 \pm 0.3$ & $\begin{array}{c}8.5 \pm 0.2 \\
\operatorname{ax}\end{array}$ & $\begin{array}{c}38.8 \pm 1.1 \\
\mathrm{ax}\end{array}$ & $\begin{array}{c}4.0 \pm 0.7 \\
\text { ay }\end{array}$ \\
\hline 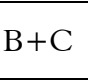 & $\begin{array}{l}9.7 \pm 3.0 \\
\mathrm{ax}\end{array}$ & $\begin{array}{c}91.7 \pm 1.8 \\
\text { by }\end{array}$ & $\begin{array}{c}90.5 \pm 0.4 \\
\text { axy }\end{array}$ & $\begin{array}{c}10.3 \pm 3.0 \\
\mathrm{ax}\end{array}$ & $\begin{array}{c}8.3 \pm 1.7 \\
\text { by }\end{array}$ & $\begin{array}{c}9.6 \pm 0.4 \\
\text { axy }\end{array}$ & $\begin{array}{c}26.3 \pm 0.9 \\
b x\end{array}$ & $\begin{array}{c}39.3 \pm 0.2 \\
\text { by }\end{array}$ & $\begin{array}{c}27.3 \pm 0.9 \\
\text { bx }\end{array}$ & $\begin{array}{c}1.8 \pm 0.2 \\
\mathrm{bx}\end{array}$ & $\begin{array}{c}4.5 \pm 0.3 \\
\text { by }\end{array}$ & $\begin{array}{c}1.5 \pm 0.4 \\
b x\end{array}$ & $\begin{array}{c}5.7 \pm 0.0 \\
b x\end{array}$ & $\begin{array}{c}7.8 \pm 0.1 \\
\text { by }\end{array}$ & \begin{tabular}{|c|}
$6.7 \pm 0.1$ \\
$b z$
\end{tabular} & $\begin{array}{l}3.5 \pm 3.3 \\
\mathrm{bx}\end{array}$ & $\begin{array}{c}34.2 \pm 0.1 \\
\text { by }\end{array}$ & $\begin{array}{c}48.9 \pm 0.1 \\
\mathrm{bz}\end{array}$ \\
\hline 马 & $\begin{array}{c}86.6 \pm 0.4 \\
b x\end{array}$ & $\begin{array}{c}1.3 \pm 0.2 \\
\text { by }\end{array}$ & $\begin{array}{c}91.6 \pm 2.6 \\
\text { ay }\end{array}$ & $\begin{array}{c}13.4 \pm 0.4 \\
b x\end{array}$ & $\begin{array}{c}8.7 \pm 0.2 \\
\text { by }\end{array}$ & $\begin{array}{c}8.4 \pm 2.6 \\
\text { ay }\end{array}$ & $\begin{array}{c}30.4 \pm 1.5 \\
c x\end{array}$ & $\begin{array}{c}34.5 \pm 0.5 \\
\text { cy }\end{array}$ & $\begin{array}{c}29.0 \pm 0.1 \\
b x\end{array}$ & $\begin{array}{c}1.0 \pm 0.6 \\
b x\end{array}$ & $\begin{array}{c}0.6 \pm 0.1 \\
\mathrm{cx}\end{array}$ & $\begin{array}{c}2.4 \pm 0.1 \\
\text { ay }\end{array}$ & $\begin{array}{c}5.5 \pm 0.0 \\
b x\end{array}$ & $\begin{array}{c}6.1 \pm 0.1 \\
\text { cy }\end{array}$ & $\begin{array}{c}6.0 \pm 0.1 \\
\text { cy }\end{array}$ & $\begin{array}{c}41.6 \pm 1.9 \\
\text { abxy }\end{array}$ & $\begin{array}{c}40.2 \pm 0.3 \\
\text { ax }\end{array}$ & $\begin{array}{c}48.4 \pm 3.3 \\
\text { by }\end{array}$ \\
\hline
\end{tabular}

PO: P. ostreatus, PSC: P. sajor-caju, PF: P. florida, B: Buğday Sapı, C: Ceviz kabuğu, Ş: Şeker pancarı posası

Her bir değer üç tekrarın ortalaması \pm standart sapma olarak gösterilmiştir $(\mathrm{n}=3, \mathrm{P}<0.05))$

a, b, c, Her bir sütunda aynı harflerle gösterilen değerler birbirinden farklı değildir.

$\mathrm{x}, \mathrm{y}, \mathrm{z}$, Her bir satırda aynı harflerle gösterilen değerler birbirinden farklı değildir 
Değişik mantar türlerinin protein içeriğinin diğer araştırıcıların bulgularından farklı olmasının temel nedeni, kültür ortamında kullanılan değişik kompost ürünlerinin kullanılması ve türlerin farklı olmasından kaynaklanmaktadır.

Lokal atıklar üzerinde kültürü yapılan $P$. ostreatus da \% 0.5-1.8 ham yağ, $P$. florida' da \% 1.5-2.4 ham yağ ve $P$. sajor-caju $\mathrm{da} \% 0.6-4.5$ ham yağ tespit edilmiştir (Tablo 1). Elde edilen ham yağ verilerinin diğer araştırıcıların verileri ile benzerlik gösterdiği ve kültür ortamına, mantar türüne bağlı olarak da değişebilir (\% 0.95-6.4) olduğu saptanmıştır (Akyüz ve Kırbağ 2010; Ragunathan ve Swaminathan 2003; Ranzai ve Sturion 1998; Morais ve ark. 2000; Crisand and Sand 1978; Bano ve Rajarathnam 1988; Yang ve ark. 2001; Rashad ve Abdou 2002; Oyetayo ve Akindahunsi 2004).

Ham kül oranı, $P$. ostreatus $\mathrm{da} \%$ 4.9-5.7, $P$. florida'da \% 4.4-6.7 ve P. sajor-caju'da \% 6.47.8 olarak tespit edilmiştir (Tablo 1-2). Değişik mantar türlerinde ham kül içeriği, mantar türüne, yetişme ortamına bağlı olarak değişiklik (\% 5.40- 13.7) göstermektedir (Akyüz ve Kırbağ 2010; Ragunathan ve Swaminathan 2003; Yang ve ark. 2001; Rashad ve Abdou 2002; Oyetayo ve Akindahunsi 2004).

Farklı mantar türlerinin yetişme ortamına ve türlerine bağlı olarak karbonhidrat içeriği \% 26.7-81.8 olarak değişmektedir (Akyüz ve Kurbağ 2010; Ragunathan ve Swaminathan 2003; Ranzai ve Sturion 1998; Morais ve ark. 2000; Crisand and Sand 1978; Bano ve Rajarathnam 1988; Yang ve ark. 2001; Rashad ve Abdou 2002; Oyetayo ve Akindahunsi 2004). Değişik tarımsal atıklar üzerinde kültürü yapılan $P$. ostreatus'da \% 38.5-43.5, $P$. florida'da \% 44.0-48.9 ve P. sajor-caju'da \% 34.2-40.2 tespit edilmiştir (Tablo 1). Elde edilen verilerin yetişme ortamına ve mantar türüne bağlı benzerlik gösterdiği, bazende değişebilir olduğu saptanmıştır.

Bazı mantar türlerinde (Pleurotus spp. ve Agaricus bisporus), türün genetiksel yapısına ve yetiştirme ortamının fiziksel ve kimyasal durumuna bağlı mantarların14.1-45.6 K, 0.21.2 Ca, 0.4-1.9 Mg, 0.2-0.9 Na gibi makro elementler ( $\mathrm{g} \mathrm{kg}-1)$; 176,5-838,0 Fe, 35,0-46,0 $\mathrm{Zn}, 4,8-65,4 \mathrm{Mn}, 6,5-21,5 \mathrm{Cu}, 0,0-11,5 \mathrm{Cr}$ ve
0,0-1,65 Cd (mg kg-1) (Akyüz ve Kırbağ 2010), Pleurotus spp.'de; 0.64-2.10 mg/g Ca, 6.1-12.7 mg/g Fe, $10.3-33.2 \mathrm{mg} / \mathrm{g} \mathrm{K}, 9.40-18.9$ $\mathrm{mg} / \mathrm{g} \mathrm{Mg}, 0.78-1.15 \mathrm{mg} / \mathrm{g} \mathrm{Na}$, ve $118-220 \mathrm{mg} / \mathrm{g}$ $\mathrm{P}$ olarak (Ragunathan ve Swaminathan 2003), P. sajor-caju'da; $4.23-6.98 \mathrm{mg} / \mathrm{g} \mathrm{Ca}, 1.09-1.90$ $\mathrm{mg} / \mathrm{g} \mathrm{Fe}, 7.74-11.88 \mathrm{mg} / \mathrm{g} \mathrm{K}, 1.09-1.90 \mathrm{mg} / \mathrm{g}$ $\mathrm{Na}, 0.09-0.34 \mathrm{mg} / \mathrm{g} \mathrm{Zn}, 0.01-0.05 \mathrm{mg} / \mathrm{g} \mathrm{Cu}$, $6.23-7.94 \mathrm{mg} / \mathrm{g} \mathrm{Mg}$ ve $7.26-11.80 \mathrm{mg} / \mathrm{g} \mathrm{P}$ (Oyetayo ve Akindahunsi 2004), P. sapidus'da; Al $95.7 \mu \mathrm{g} / \mathrm{g}$, B $13.5 \mu \mathrm{g} / \mathrm{g}$, Ba $5.59 \mu \mathrm{g} / \mathrm{g}$, Cd 0.42 $\mu \mathrm{g} / \mathrm{g}$, Co $0.10 \mu \mathrm{g} / \mathrm{g}$, Cr $1.50 \mu \mathrm{g} / \mathrm{g}, \mathrm{Cu} 90.9 \mu \mathrm{g} / \mathrm{g}$, Fe $227 \mu \mathrm{g} / \mathrm{g}$, La $0.90 \mu \mathrm{g} / \mathrm{g}, \mathrm{Mg} 2170 \mu \mathrm{g} / \mathrm{g}, \mathrm{Mn}$ $0.85 \mu \mathrm{g} / \mathrm{g}$, Ni $0.44 \mu \mathrm{g} / \mathrm{g}, \mathrm{P} 10.161 \mu \mathrm{g} / \mathrm{g}, \mathrm{Pb} 2.59$ $\mu \mathrm{g} / \mathrm{g}$, Sr $0.05 \mu \mathrm{g} / \mathrm{g}$, Ti $5.72 \mu \mathrm{g} / \mathrm{g}$ ve Zn $80.3 \mu \mathrm{g} / \mathrm{g}$ olarak tespit edilmiştir (Zhang ve ark. 1995a). P. djamor $^{2} \mathrm{da}$; Ca $1270 \mu \mathrm{g} / \mathrm{g}, \mathrm{P} 7780 \mu \mathrm{g} / \mathrm{g}, \mathrm{K} 13.000$ $\mu \mathrm{g} / \mathrm{g}$, Na $380 \mu \mathrm{g} / \mathrm{g}$, Fe $478 \mu \mathrm{g} / \mathrm{g}, \mathrm{Mg} 1100 \mu \mathrm{g} / \mathrm{g}$, Zn $200 \mu \mathrm{g} / \mathrm{g}$, Cu $46 \mu \mathrm{g} / \mathrm{g}$, Mo $0.2 \mu \mathrm{g} / \mathrm{g}$, Mn 32 $\mu \mathrm{g} / \mathrm{g}$ olarak değişiklik göstermektedir (Zhang ve ark. 1995b). Kültürü yapılan $P$. ostreatus'da; $102.9-176.6 \mathrm{mg} / \mathrm{kg} \mathrm{Na}, 194.7-239.9 \mathrm{mg} / \mathrm{kg} \mathrm{K}, 0-$ $40 \mathrm{mg} / \mathrm{kg} \mathrm{Cu}, 53-739 \mathrm{mg} / \mathrm{kg} \mathrm{Fe}, 280-508 \mathrm{mg} / \mathrm{kg}$ $\mathrm{Zn}, 3.51-14.65 \mathrm{mg} / \mathrm{kg} \mathrm{Pb}$. P. florida' da 128.4$185.2 \mathrm{mg} / \mathrm{kg} \mathrm{Na}, 344.4-379.4 \mathrm{mg} / \mathrm{kg} \mathrm{K}, 0-459$ $\mathrm{mg} / \mathrm{kg}$ Fe, 387-413 mg/kg Zn, 0.98-3.95 mg/kg $\mathrm{Pb}$ ve $P$. sajor-caju'da ise $90.1-136.9 \mathrm{mg} / \mathrm{kg} \mathrm{Na}$, $166.0-401.7 \mathrm{mg} / \mathrm{kg} \mathrm{K}, 0-545 \mathrm{mg} / \mathrm{kg}$ Fe, 310-425 $\mathrm{mg} / \mathrm{kg} \mathrm{Zn,} 0.0-1.98 \mathrm{mg} / \mathrm{kg} \mathrm{Pb}$ içerdiği, fakat tüm türlerde ise $\mathrm{Co}, \mathrm{Mn}, \mathrm{Cu}$ ve $\mathrm{Ni}$ gibi toksik metaller ise tespit edilmemiştir (Tablo 2). Elde edilen bu verilerin, diğer mantar türlerinin verileri ile karşılaştırıldığında, türün yetişme ortamına ve genetiksel yapısına bağlı olarak değiştiği saptanmıştır (Tablo 2).

Sonuç olarak; farklı tarımsal atıkların mantar kültüründe kolaylıkla değerlendirilebileceği, ceviz ve şeker pancarı posası gibi endüstriyel atıklarında katkı maddesi olarak kulanılarak, mantarların besinsel değerlerinin zenginleştirilebileceği saptanmıştır.

Teşekkür: $\mathrm{Bu}$ çalışma; Fırat Üniversitesi Bilimsel Araştırma Projeleri Birimi (FÜBAP, Proje No:1679) tarafindan desteklenmiştir. Katkılarından dolayı Y. Doç.Dr. Mehmet AKYÜZ'e teşekkür ederiz. 
Değisik Tarımsal Atıkların Bazı Kültür Mantarı Türlerinin Besin Değerleri Üzerine Etkisi

Tablo 2. Lokal Tarımsal Atıklar Üzerinde Kültürü Yapılan Bazı Mantar Türlerinin Element Düzeyleri

\begin{tabular}{|c|c|c|c|c|c|c|c|c|c|}
\hline \multirow{2}{*}{$\begin{array}{l}\text { Elementler } \\
(\mathrm{mg} / \mathrm{kg}\end{array}$} & \multicolumn{3}{|c|}{ P. ostreatus } & \multicolumn{3}{|c|}{ P. florida } & \multicolumn{3}{|c|}{ P. sajor-caju } \\
\hline & $\mathrm{B}$ & $\mathrm{B}+\mathrm{S}$ & $\mathrm{B}+\mathrm{C}$ & $\mathrm{B}$ & $\mathrm{B}+\mathrm{S}$ & $\mathrm{B}+\mathrm{C}$ & $\mathrm{B}$ & $\mathrm{B}+\mathrm{S}$ & $\mathrm{B}+\mathrm{C}$ \\
\hline $\mathrm{Cu}$ & 40 & - & - & - & - & - & - & - & - \\
\hline Co & - & - & - & - & - & - & - & - & - \\
\hline $\mathrm{Mn}$ & - & - & - & - & - & - & - & - & - \\
\hline $\mathrm{Ni}$ & - & - & - & - & - & - & - & - & - \\
\hline $\mathrm{Fe}$ & 739.0 & 479.0 & 53.0 & 459.0 & - & - & - & - & 545 \\
\hline $\mathrm{Zn}$ & 400.0 & 508.0 & 280.0 & 401.0 & 413.0 & 387.0 & 425 & 418 & 310 \\
\hline $\mathrm{Pb}$ & 14.65 & 7.16 & 3.51 & 3.95 & 1.96 & 0.98 & - & 1.85 & 1.98 \\
\hline $\mathrm{Na}$ & 146.6 & 176.6 & 102.9 & 128.4 & 185.2 & 146.862 & 90.102 & 136.929 & 104.292 \\
\hline $\mathrm{K}$ & 208.1 & 239.9 & 194.7 & 350.8 & 379.4 & 344.4 & 401.7 & 274.3 & 166.0 \\
\hline
\end{tabular}

B: Buğday Sapı, C: Ceviz kabuğu, Ş: Şeker pancarı posası 


\section{KAYNAKLAR}

Akyüz M, Kırbağ S (2010) Nutritive value of wild edible and cultured mushrooms. Turk. J. Biol. 34: 97-102.

AOAC (1990) Official methods of analysis (15 th ed.). Virginia DC, USA: Association of agricultural chemist, 746-780 pp.

Bano Z, Bhagya S, Srinivasa KS (1981) Essential amino acid composition and proximate analiyses of the mushroom Pleurotus eous and $P$. florida, Mushroom Newsletter the Tropics, 1(3): 6-10.

Bano Z, Rajarathnam S (1988) Pleurotus mushrooms. Part II. Chemical composition, nutritional value, post-harvest physiology, preservation, and role as human food, CRCCritical Reviews in Food Science and Nutrition, 27: 87-158.

Breene WM (1990) Nutritional and medicinal value of speciality mushrooms, Journal of Food Protection, 53 (10): 883-894.

Chang ST, Miles DG (1989) The nutritional attributes and medicinal value of edible mushrooms. In edible mushrooms and their cultivation, CRC Press, Boca Raton, FL, 27-40 pp.

Cohen R, Persky L, Hadar Y (2002) Biotechnological applications and potential of wood-degrading mushrooms of the genus Pleurotus, Applied Microbiology and Biotechnology, 58: 582-594

Crisand EW, Sands A (1978) Nutritional value, In: The biology and cultivation of edible mushrooms (eds S.T., Chang, W.A., Hayes), Academic Press, New York, 172-189 and 727-793 pp.

Çağlarırmak N (2007) The nutrients of exotic mushrooms (Lentinus edodes and Pleurotus species) and an estimated approach to the volatile compounds, Food Chemistry, 105: 1188-1194.

Diez VA, Alvarez A (2001) Compositional and nutritional studies on two wild edible mushrooms from Northwest Spain, Food Chemistry, 75: 417-422

Ergün A, Çolpan İ, Yıldız G, Küçükersan S, Tuncer SD, Yalçın S, Küçükersan MK, Şehu A (2004) Yemler, Yem Hijyeni ve Teknolojisi, Ankara Üniversitesi Veteriner Fakültesi Hayvan Besleme ve Beslenme Hastalıkları Anabilim Dalı. II. Baskı, Bölüm 8, 354391 s., ISBN 975-97808-0-1.

Gücin F, Tamer AÜ ( 1997) Mikolojiye giriş, Uludağ Üniversitesi, Fen Edebiyat Fakültesi Ders Notları, Bornova, 1-195 s.

Kırbağ S, Korkmaz V (2013) Sellülozik Atıkların Pleurotus spp.'nin Gelişim Periyodu ve Verimi Üzerine Etkileri. Artvin Çoruh Üniversitesi Orman Fakültesi Dergisi: 14: 239-244.

Küçükomuzlu B, Pekşen A (2005) Yetiştirme ortamı ağırlıklarınının Pleurotus mantar türlerinin verim ve kalitesi üzerine etkileri, OMÜ Ziraat Fakültesi Dergisi, 20 (3), 64-71.

Manzi P, Aguzzi A, Vivanti V, Paci M, Pizzoferrato L (1999) Mushrooms as a source of functional ingredients. Euro Food Chemistry 10. Europien Conference on: Functional foods, A new challenge fort the food chemist, Budapest, 1;89-93.

Mattila P, Suonpaa K, Piironen V (2000) Functional properties of edible mushrooms, Nutrition, 16 (78); 694-696.

Mattila P, Konko K, Eurola M, Pihlava J M, Astola J, Vahteristo L, Hietaniemi V, Kumpulainen J, Valtonen M, Piironen V (2001) Contents of vitamins, mineral elements and some phenolic compounds in cultivated mushrooms, Journal of Agriculture and Food Chemistry, 49: 2343-2348.

Morais MH, Ramos AC, Matos N, Santos-Oliveira EJ (2000) Note: production of shiitake mushroom (Lentinus edodes) on lignocellulosic residues, Food Science and Technology International, 6: 123-128.

Oyetayo FL, Akindahunsi AA (2004) Nutrient distribution in wild and cultivated edible mushroom, Pleurotus sajor-caju, Food, Agriculture and Environment, 2: 166-168.

Ragunathan R, Gurusamy R, Palaniswamy M, Swaminathan K (1996) Cultivation of Pleurotus spp. on various agro-residues, Food Chemistry, 55: 139-144.

Ragunathan R, Swaminathan K (2003) Nutritional status of Pleurotus spp. grow on various agro-wastes, Food Chemistry, 80: 371-375.

Ranzani MR, Sturion GL (1998) Amino acid composition evaluation of Pleurotus spp. cultivated in banana leaves, Archivos Latinoamericanos de Nutrición, 48: 339-348.

Rashad MM, Abdou HM (2002) Production and evaluation of Pleurotus ostreatus mushroom cultivated on some food processing wastes, Advances in Food Sciences, 24 (2): 79-84.

Yang JH, Lin HC, Mau JL (2001) Non-volatile taste components of several commercial Mushrooms, Food Chemistry, 72: 465-471.

Yıldız A, Karakaplan M (2003) Evaluation of some agricultural wastes for the cultivation of edible mushrooms: Pleurotus ostreatus var. salignus, Journal of Food Science and Technology-Mysore, 40: 290-292.

Zhang CX, Zheng YL, Li XG, Xu CL (1995a) Study on nutrient contents of Pleurotus sapidus (Schulz) Sacc. (in Chinese with English abstract), Journal of Jilin Agricultural University, 17 (4), 24-25.

Zhang QC, Huang YY, Lai WN, Lin Q (1995b) Analysis on the nutritional components of red oyster mushroom RO-1 (in Chinese), Edible fungi, 17 (4): 12 . 